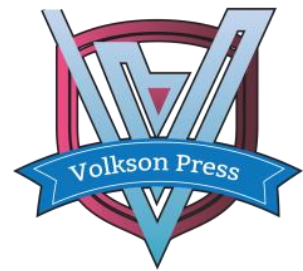

Contents List available at VOLKSON PRESS

Economics \& Management Innovations(EMI)

DOI : http://doi.org/10.26480/icemi.01.2017.291.292

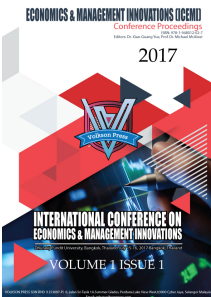

\title{
Study on the Development of Agricultural Product Logistics in Hubei Province under the Thinking of Internet
}

Qiong-jie ZHOU ${ }^{1, *}$,Yan $\mathbf{L i}^{2}$,a

${ }^{1}$ Wuhan Donghu University,301wenhua Road, jiangxia District, Wuhan,430212,Hubei,China

${ }^{2}$ Wuhan Business College, No 634 hung Chu street,Hongshan District, Wuhan430212,Hubei,China

aCorresponding author*email: 215746122@qq.com

This is an open access article distributed under the Creative Commons Attribution License, which permits unrestricted use, distribution, and reproduction in any medium, provided the original work is properly cited.

\section{ARTICLE DETAILS}

\section{Article History:}

Received 02 october 2017 Accepted 06 october 2017 Available online 11 october 2017

Keywords:

thinking of Internet; agricultural product logistics ; logistics development.

\section{ABSTRACT}

With rich agricultural resources and unique geographic location, Hubei province, however, hasn't fully shown its advantages. Such problems vastly exit, as high cost, low technological level, service lacking multiform, limited marketing development, employees of low quality, lack of professional talents, etc. In the thinking of Internet, this paper suggests relying on perfect logistics infrastructure and high-end preservation technology of agricultural products and puts forward to break the traditional and regional limitations, optimize and integrate the resources, innovate boldly, comprehensively solve policy suggestions for the "last one kilometer" of agricultural products.

\section{Introduction}

Internet Thinking, in the context of the mobile internet, the big data, and the cloud computing, develops as a way of re-examining the market, consumers, products, enterprise value chain, even the entire business ecosystem. With the aim to satisfy the consumers' demands and process agricultural entities and relevant information, agricultural products logistics is actually physical flow from producers to consumers; that is, farm products, the subjects, via various postpartum logistics links, are ultimately delivered to the consumers without decreasing their values. Agricultural products, affected by the natural environment, like seasonal effects, temperature, humidity, etc., are easily damaged and decaying in transportation, and the cost therefore increases. Agricultural product Logistics, as the bridge connecting agricultural products and consumers, reduces logistics costs and improves logistics efficiency, plays an important role in promoting economic development. Hubei Province serves as the major base of agricultural products such as cotton and oil products of China, enjoying its high reputation of national breadbasket. It will be of great importance through the Internet Thinking to look into ways to accelerate their agricultural currency, shorten the circulation period, guarantee freshness and quality safety of agricultural products, enhance the user experience, and promote the industrial development of agriculture.

2. Current situations of agriculture products logistics in Hubei provice

2.1 Unique geographical environment laying the foundation for the development of agricultural products logistics

Hubei Province, known as "the thoroughfare leading to nine provinces" and "the province with a thousand lakes", has unique advantage by water. It is in the middle reaches of the Yangtze River, north of Dongting Lake, north to Henan, Anhui to the East, Southeast and south to Jiangxi and Hunan, west to Chongqing, adjacent to Shanxi in the northwest. Wuhan, the capital city, is the major production base of grain, cotton, and oil, and the largest production base of freshwater products. The advantage of regional transportation is quite obvious, and the transportation route has formed stereo structural transport network of water, land and air, represented by highway, water, rail, and air. In 2014, Hubei province had an increase of $9.2 \%$ in transportation, storage and postal industry in the tertiary industry; the cargo turnover was 5798.12 billion tons $/ \mathrm{km}$, with an increase of $15.1 \%$ over the previous year. Vertically speaking, the railway operating mileage is 4060 kilometers in Hubei province, ranking the twelfth in the whole country and the third among six Mid-China provinces. The total mileage of highway traffic has reached 5106 kilometers; Xingang Wuhan container freight volume has exceeded one million marks and become the largest container port in the upper-middle reaches of Yangtze River.

\subsection{Abundant agricultural products resources in urgent need of} rapid development of logistics industry

According to "the Statistical Communiqué Of Hubei Province on the 2014 National Economy and Social Development ", the planting area of grain in 2014 was 4.3703 million hectares, an increase of 0.1679 million hectares compared with the previous year; the planting area of cotton was 0.3448 million hectares, a decrease of 0.1062 million hectares; the planting area of oil-bearing crops was 1.5425 million hectares, an increase of 0.0256 million hectares. The total output of grain was 25.8416 million tons, an increase of 0.8286 billion tons compared with the previous year; the total output of cotton was 0.3595 million tons, a decrease of 0.1002 billion tones, $21.8 \%$; the output of oil crops was 30419 billion tons, an increase of 0.0873 billion tons, $2.6 \%$. Animal husbandry and aquaculture grew steadily. The province's annual amount of pig slaughter is 44.7511 million, increasing by $5.6 \%$. Aquatic products output reached 4.33 million tons, increasing by $5.6 \%$. Such abundant agricultural products resources call for rapid development of agricultural products processing industry in Hubei province. With the increasing demand of agricultural products, farmers gradually avail themselves of the Internet, which has broadened circulation channels for agricultural products and diversified marketing methods. On the whole, the key factor of agricultural product e-commerce development is accompanying agricultural products logistics. Backward reasoning shows that the development of agricultural economy is the basis of the development of agricultural product logistics and therefore promotes the logistics development.

3. Analysis of restrictive factors of agricultural product logistics development in Hubei provice

Hubei province has unique transportation advantage and agricultural product logistics is developing rapidly, but there still exist problems urgently to be solved, such as high circulation costs, backward 
infrastructure, low technological level, lack of leading corporation, service lacking multiform, limited marketing development, employees of low quality, lack of professional talents, poor logistics environment, policies not fully implemented, etc.

\subsection{Backward infrastructure, low level of technology}

Compared with other provinces whose logistics system is more developed, wholesale farm product market in rural areas in Hubei provinces disconnects with major cities. The enquiry to sellers shows that professional market of agricultural products, which simply provides sites for sale, is not special actually, low-graded, and with few professional equipments. The specific process is as follows: sellers in cities send commissioners for products in producing areas; the products are then stored in the warehouse; commissioners connect logistics company which will arrange vehicles to load and transport the products. Such a process makes the freshness of agricultural products difficult to preserve and exposes the following problems: lack of large-scale storage and refrigerators, underdeveloped transport conditions and equipment, few special purpose vehicles which are efficient, low level of the mechanization in loading and unloading, imperfect wholesale market of agricultural products.

\subsection{Service lacking multiform and limited market development}

The mode of agricultural products logistics in Hubei Province is mainly in form of direct sales and contract sales. Direct sale, which has less intermediate links, lower transaction cost and retail prices, is not helpful to improve the market share of agricultural products, less capable in avoiding market risks and therefore cannot meet the needs of economic and social development. For processing enterprises, large chain supermarkets and farm product market wholesalers, contract logistics mode, which overcomes the problem of instable raw material sources, enables enterprises to have stable raw material resources, improves the ability to control resources and producing stability, finds comparatively stable selling channels and better controls product quality. Nevertheless, the interest of farmers under this model is easily infringed; the market transaction and distribution cost is still very high; the interest connection is very loose; defaults are likely to happen. At present, the overall situation of agricultural product logistics industry in Hubei province is characterized by self - oriented logistics, mode lacking variety, low level of profession and socialization.

\subsection{Less qualified employees and lacking professional talents}

Till now, there has been some representative agricultural logistics company, such as Wuhan Badatong Agricultural Products Logistics Co. Ltd., Wuhan City Circle Haijixing Agricultural Products Logistics Co. Ltd., Wuhan Mountain Green Logistics Company, Wuhan Million Tons of Cold Storage Logistics Company, Wuhan JiaheXin agricultural logistics Co. Ltd. and so on, but they don't have an overall and long-term layout. There is no uniform pace among the third party logistics companies, no sufficient communication, cooperation and coordination among enterprises, no enough logistics professionals who are, for instance, talented in technological guidance and proposing, technological introduction and innovation, management informatization and system network, no timely communication between enterprises and National Agricultural Products Logistics Engineering Technology Research Center, resulting in comparative underdevelopment and low-graded duplicate construction of the third party logistics in Hubei province.

\section{Policy proposals promotion the development of agricultural products logistics}

The development of agricultural products logistics mush lay foundation on the perfect logistics infrastructure, high-end agricultural preservation technology to reduce loss, decrease logistics cost and improve logistics efficiency. Accordingly, we need to find foothold in the Hubei market, expand the national market, follow economic laws, break the limitations of traditional industry and regions, optimize and integrate the resources, innovate boldly, comprehensively solve the problem of "the starting one kilometer" and "the last one kilometer".

4.1 Enhancing investment in infrastructure of modern agricultural product logistics
4.2 Encouraging cooperation between colleges and enterprises to cultivate logistics talents together

According to the flow of logistics professional talents in Hubei Province colleges and universities are found to emphasize the training of specialists in the field of logistics, encourage innovation and entrepreneurship, support agricultural e-commerce and simulate logistics base of agricultural products, have basic knowledge experience in the logistics personnel training, but are lack of practical experience. On the other hand, enterprises attach importance to technical practice rather than theoretical basis. Colleges and enterprises should establish cooperating relationship, work together to make personnel training plans, cultivate together professional and technical personnel focusing on both theories and practice. Enterprises should be active to sponsor competitive and practical activities, set up a professional lifelong education system in logistics industry and carry out professional training activities, etc. This is an important step in the development of logistics.

\subsection{Taking the path of agricultural product logistics with Hubei} characteristics

At present, most of the logistics vehicles in Hubei are contacted by means of telephone in logistics companies. To reduce the time cost for connection and communication, this paper suggests installing GPS device or using mobile phone App software localization to report location and distance of logistics vehicles. Mobile phone software dependent can be used to spread (one-to-many) and receive ( many to one)information which is then filtered, and the feedback will be sent to the customers. In this way, we can skip the step of connecting logistics drivers and save time and money. Meanwhile small and medium-sized logistics enterprises can integrate resources, foster the subject of agricultural product logistics together, increase the degree of organization, make the third party logistics enterprise system dominate the socialized and specialized agricultural product logistics services, and actively adopt high-end agricultural product logistics technology, as cold chain logistics distribution services, to ensure the quality and safety of agricultural products and tasty freshness, reduce loss and increase profits.

\subsection{Playing the full role of SMC as the main channe}

Rural logistics network with SMC as the main channel should be constructed and modified; efforts should be intensified to build subordinate comprehensive services at the village level which are expected to cover all administrative villages and in this way to go through "the last kilometer" rural logistics network; make full use of traditional advantages SMC and service network, supporting its function to be diversified; create a new situation in which SMC is the main hinge point, postal logistics, transport logistics, third-party logistics and other logistics forms participate to complement each other's advantages and integrate resources; strengthen the construction of electronic commerce application terminal of convenience agencies at all levels in the SMC system; reduce transaction costs. Two-way flow pattern of "the third party logistics plus postal logistics", the joint pattern of "agricultural schools, agricultural supermarkets and agricultural enterprises" and two-way flow pattern of "leading enterprises of agricultural industrialization plus farmers" are good examples of this kind.

\section{Acknowledgement}

This work was supported by the grants from Hubei Provincial Collaborative Innovation Centre of Agricultural E-Commerce (under Construction) (Wuhan Donghu university research [2015] No. 11 Document).

\section{References}

[1] Duan Lijie. Research on Hubei Agricultural Product Logistics Construction in E-commerce Environment [J].Journal of Logistics Engineering and Management. 2013(10):142-144

[2] Zhao Lijuan. On Collaborative Interaction Between E-commerce and Logistics [J]. Journal of Commercial Age. 2014( 1):43-44

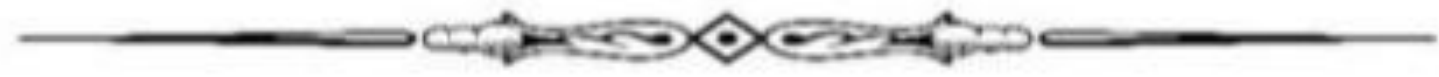

